\title{
Framework for planning the mobility service based on autonomous vehicles
}

\author{
Dávid Földes, Csaba Csiszár
}

\begin{abstract}
Autonomous vehicles (AVs) facilitate alteration in the passenger transportation. Shared, demand-driven mobility services based on small-capacity AVs emerge in urban areas. In order to provide highly personalized services and to enhance the acceptance of AVs, the user expectations are to be revealed. The research question is what kind of information is needed to plan various service types with the consideration of user expectations and operational constraints. Accordingly, the planning functions, as well as their input and output data have been identified. Then, the connections between the functions have been explored. In order to provide input data for planning functions, we have elaborated a data collection method applying a questionnaire survey with stated preferences. Based on the survey data correlations could be revealed between socio-demographic characteristics or mobility habits and expected mobility service attributes. The results can be used as a framework for planning mobility services based on AVs.
\end{abstract}

Index Terms-autonomous vehicles, service planning, questionnaire survey, user expectation, stated preference

\section{INTRODUCTION}

$\mathrm{T}$ HE current megatrends (e.g. urbanization) imply an alteration in transportation systems. In smart city concepts, mobility is considered as one of the most relevant focus areas because it has several complex relations to the other subsystems and affects significantly the entire operation of a city. The alteration of the travel modes and habits are speeded up by autonomous vehicles (AVs). Shared mobility service emerges, which is called according to our definition STA - Shared Transportation based on small-capacity AVs. This service is highly personalized, demand-driven (or demand-responsive), and accessible via mobile application. The differences between demand-driven and demandresponsive mobility forms have been identified according to [1], [2]. Demand-driven (or on-demand) services are operated only if travel purposes are registered (e.g. taxi); the route and timetable are not predetermined. Demand-responsive services are operated by flexible timetable and capacity according to volume of current demand; in many cases the route is predetermined. Expectedly, the individual car ownership

This work was supported by the ÚNKP-17-3-I New National Excellence Program of the Ministry of Human Capacities.

D. Földes and Cs. Csiszár are with the Department of Transport Technology and Economics (KUKG), Faculty of Transportation Engineering and Vehicle Engineering (KJK), Budapest University of Technology and Economics (BME), Budapest, Hungary (e-mails: foldes.david@mail.bme.hu, csiszar.csaba@mail.bme.hu). decreases significantly $[3,4]$. Private AVs are used only for the most flexible travel purposes.

AVs are driver-less vehicles equipped with advanced hardware (e.g. camera, sensor) and software (e.g. artificial intelligence) elements. AVs make decisions based on collected information and using cognitive capability. We consider that the autonomy is a relative concept. Although the vehicles are able to make individual decisions in traffic, their operational management requires so-called mobility centers [5]. Modifications (e.g. application of virtual lights) are needed in traffic control [6], and new traffic management policies are necessary to optimize trajectories, speeds and routes [7].

The planning and operation of STA require several data. In the early phase, the historical operational data are still not available. User expectations have to be considered during the planning to improve the acceptance towards the new mobility service and AVs, too. Our aim was to model the information system for planning of mobility service based on AVs. The research questions were:

- what service types of STA are to be defined?

- what are the challenges and novelties during planning?

- what is the information requirements of the functions?

- how can user expectations be measured and considered during planning?

Accordingly, the remainder of the paper is structured as follows. State of the art section provides literature review in Section II. Then, the research methodology is described in Section III. In Section IV, the results are summarized and discussed, namely the STA types, the planning functions, the model of the information system for planning as well as the data collection and process method regarding user expectations. The paper is completed by the concluding remarks including future research directions.

\section{STATE OF THE ART}

Measuring the acceptance of mobility services based on AVs is difficult because of the bare number of existing solutions. Users have only assumptions and cannot adequately imagine it; therefore, they can compare such a service with only the current ones. Stated preferences are applied to measure expectations. The acceptance has different dimensions (e.g. willingness to use, actual use) and alters in time (before use, during, and after use). Individual acceptance (we are ready to use) and societal acceptance (whole society accept a transportation system which uses AVs) are different [8]. Merat et al. [9] introduced acceptability and acceptance 
notions. Acceptability is the synonym of willingness to use (expectation). Acceptance expresses the revealed preference after the user tried an AV. The aim of the literature review was to reveal what questions should be incorporated into our survey to support planning functions.

User's acceptability towards services based on AVs has been analyzed by several surveys. Acceptability is predominantly influenced by the perceived usefulness, effort expectancy, ease of use and social influence [10]. There is a strong correlation between individual's modal split and willingness to choose a shared service based on an AV [11]. Service attributes including travel cost, travel time and waiting time may be critical factors for the use of shared AVs [12] The lack of personnel would be one of the most concerned issues (e.g. security) [13]. The user trust can be improved by providing hands-on experience about systems [9]. The reactions to service based on AVs were positive as part of the project CityMobil2 [14]. The users could envision it as a feeder mobility service to public transportation [15].

The mobility service based on shared AV is more effective in urban areas where the income is average; and it is more popular among university students [16]. AVs can be applied in low population density areas as a door-to-door transport or in high population areas as a feeder service [17]. The size of an AV fleet, the capacity of an on-board battery and a charging infrastructure were suggested in an example area for taxi service without considering the user opinion [18].

The current studies deal with the general user acceptance but with less focus on the planning of mobility service. Current mobility habits and several socio-demographic characteristics (e.g. income) predominantly influence expectations and acceptability towards services based on AVs. General mobility service attributes (walking and waiting time, cost) should be especially highlighted during the planning.

\section{Methodology}

We determined and applied the following steps during our research:

A. Definition and characterization of STA service types based on our deliberations and literature. Two types of shared mobility services based on AVs are considered to replace individual car use providing occasionally a door-to-door but mostly a feeder service: shared minivan with 8 seats and shared minibus with 16 seats [19]. In other studies, small capacity autonomous pods are considered also as a feeder service [10], [12]. Furthermore, autonomous cars may provide last-mile service with or without seat capacity sharing [11].

B. Identification of planning functions considering the characteristics of types. The novelties of the functions have been revealed which should be considered during their elaboration. The conventional system and service planning methods [20] alter as the consequence of the more complex system structure, the new and unknown technology, the dynamism of the data and the expectations towards more adaptive, sustainable and flexible systems.

C. Modeling the information system of planning. The input, output data, and connections have been determined. Integrated systems and coordinated procedures are needed to exploit the obvious potentials of AVs [21]. The data keep the system components together [5], therefore the identification of the data groups has high relevance.

D. Determination of the data collection and process method regarding user expectations. A survey-based method for planning sustainable transportation system [22] was considered as a basis. Accordingly, a questionnaire survey is going to be executed to reveal user expectations towards STA types. The structure of the questionnaire has been prepared to provide input data for planning.

\section{RESULTS AND DISCUSSION}

\section{A. STA service types}

We identified and characterized the service types. Either direct service or feeder service to arterial lines is provided. The traditional, high-capacity, arterial public transportation, such as underground, tram, bus, remains in future as high demand can be satisfied efficiently in this way [11], [19]. Practically, all transitional modes (e.g. taxi, car-sharing, ridesharing, ride-sourcing, chauffeur service) are merged into STA. This service can meet some demand derived also from individual car use. STA belongs to public transportation, but this term is to be re-defined. The vehicles may be owned by a public agency, a private company, or any third-party organization. Small capacity vehicles are applied. Two different sized vehicles are distinguished: car (max. 4 passengers) or mini-bus which is usually called 'pod' (5-15 passengers). A flexible tariff system is an effective tool to influence the demand and supply; thus, the efficiency of the service can be enhanced [23]. The rates may depend on the type of the service as well as the current demand and capacity. The defined STA types are illustrated on Fig. 1. The characterization of types is summarized in Table I.

$\mathrm{S}_{1}$ taxi: provides individual door-to-door service between any departure and arrival points without capacity sharing.

$\mathrm{S}_{2}$ shared taxi: provides door-to-door service between any departure and arrival points with capacity sharing.

$\mathrm{S}_{3}$ feeder pod: provides feeder service from any departure points in a zone to the stop of a high capacity line; transfers are guaranteed by semi-fixed timetable. The operation is symmetric in the opposite direction (from the stop of a high-capacity line to any arrival points).

$\mathrm{S}_{4}$ fixed route pod: provides mostly feeder service on fix route. The departure and arrival points are fix stops. It is operated according to timetable, but additional departures may be inserted according to demands.

Designated meeting points [24] can be introduced by the type $S_{2}$ and $S_{3}$. In this case, AVs stop near to the user's departure point (only a small walking distance is required). So, the efficiency of the service can be improved. The designated points can be used where the structure of the roads requires it (e.g. dead-end road) or where the travel demands are concentrated (e.g. blockhouses).

The time utilization and seat capacity utilization of STA vehicles are high. The vehicles serve several demands in a day (sharing in time) and during a run (seat capacity sharing). 


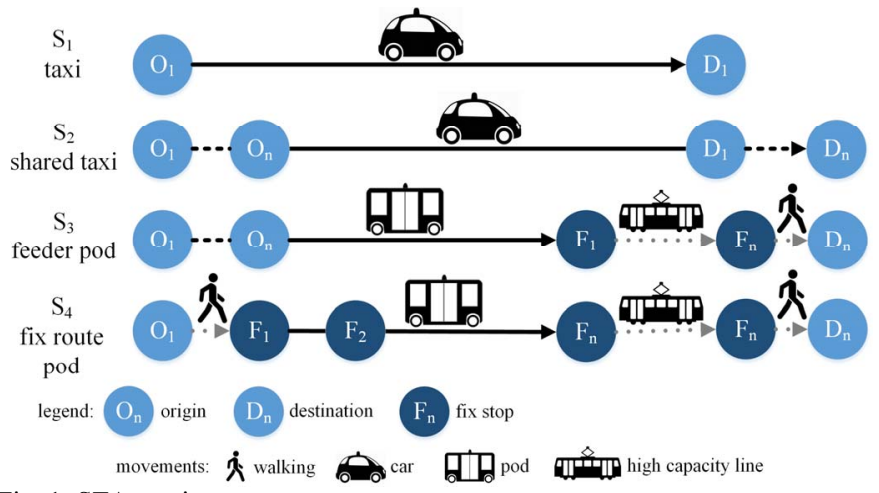

Fig. 1. STA service types

TABLE I

Characterization of STA Service Types

\begin{tabular}{|c|c|c|c|c|}
\hline & $\begin{array}{l}\mathrm{S}_{1} \\
\text { taxi }\end{array}$ & $\begin{array}{c}\mathrm{S}_{2} \\
\text { shared } \\
\text { taxi }\end{array}$ & $\begin{array}{c}\mathrm{S}_{3} \\
\text { feeder pod }\end{array}$ & $\begin{array}{c}\mathrm{S}_{4} \\
\text { fix route pod }\end{array}$ \\
\hline vehicle type & car & car & pod & pod \\
\hline $\begin{array}{l}\text { sharing } \\
\text { modality }\end{array}$ & $\begin{array}{l}\text { no } \\
\text { door-to- } \\
\text { door }\end{array}$ & $\begin{array}{l}\text { yes } \\
\text { door-to- } \\
\text { door }\end{array}$ & $\begin{array}{l}\text { yes } \\
\text { feeder }\end{array}$ & $\begin{array}{l}\text { yes } \\
\text { feeder }\end{array}$ \\
\hline capacity & $\begin{array}{l}\text { demand- } \\
\text { driven }\end{array}$ & $\begin{array}{l}\text { demand- } \\
\text { driven }\end{array}$ & $\begin{array}{l}\text { rather demand- } \\
\text { driven }\end{array}$ & $\begin{array}{l}\text { demand- } \\
\text { responsive }\end{array}$ \\
\hline scheduling & flexible & flexible & $\begin{array}{l}\text { semi-fix } \\
\text { (guaranteed } \\
\text { transfer) }\end{array}$ & $\begin{array}{l}\text { fix } \\
\text { (additional } \\
\text { departures) }\end{array}$ \\
\hline boarding point & flexible & flexible & $\begin{array}{l}\text { semi-fix (only } \\
\text { in zone) }\end{array}$ & fix stop \\
\hline alighting point & flexible & flexible & fix stop & fix stop \\
\hline route & flexible & flexible & $\begin{array}{l}\text { semi-fix (fix } \\
\text { arrival point) }\end{array}$ & fix \\
\hline access walking & no & no & no & yes \\
\hline egress walking & no & no & yes & yes \\
\hline
\end{tabular}

\section{B. Planning functions}

We identified and summarized the planning functions for the specified STA types on Fig. 2. The function categories are as follows:

- preliminary service planning:

0 basic service planning $\left(\mathrm{P}_{\mathrm{A}}-\mathrm{P}_{\mathrm{E}}\right)$,

$\circ$ information service planning $\left(\mathrm{P}_{\mathrm{F}}-\mathrm{P}_{\mathrm{H}}\right)$,

- operative planning $\left(\mathrm{P}_{\mathrm{I}}-\mathrm{P}_{\mathrm{J}}\right)$.

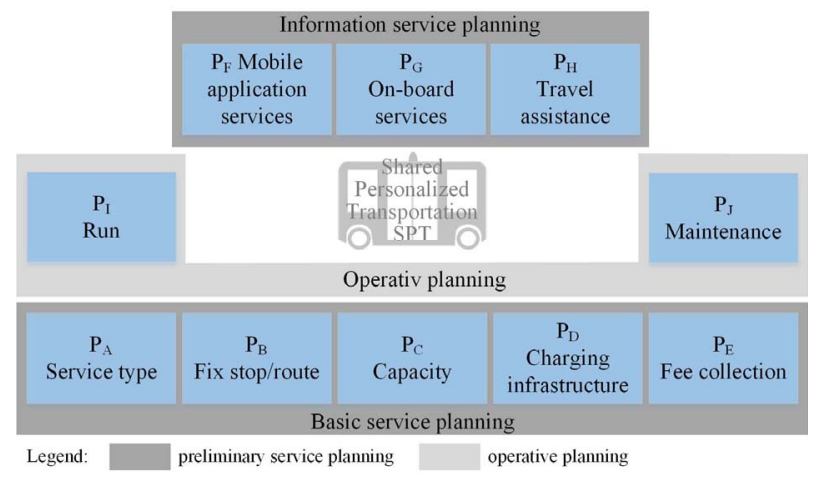

Fig. 2. Planning functions

Although planning functions of STA are similar to those of mobility service based on traditional vehicles, they have several novelties. Whereas drivers' work regulations do not have to be considered, the lack of personnel attendance causes several new challenges both in management (e.g. energy charging) and passenger handling (e.g. safety). Real-time demand-capacity coordination, service personalization, and vehicle charging are the most relevant operational challenges. Most of the functions can be automatized either partially or entirely. Challenges and novelties are summarized according to functions:

$\mathrm{P}_{\mathrm{A}}$ : the service types of STA are selected and planned. Tra vel demands and expectations are based only on the stated preferences and forecasting.

$\mathrm{P}_{\mathrm{B}}$ : the location of fix stops or designated waiting points (type $S_{2}, S_{3}$ ), route (type $S_{4}$ ), and served area (type $S_{3}$ ) are determined based on the analysis of territory (e.g. location of service points). The demand is forecasted for longer terms.

$\mathrm{P}_{\mathrm{C}}$ : the timetable is planned (type $\mathrm{S}_{3}, \mathrm{~S}_{4}$ ) and the vehicle number is determined. Especially, the time periods with the highest demand (peak hours) should be revealed; and this demand should be met during the planning of supply. The demand is forecasted for medium or short terms.

$\mathrm{P}_{\mathrm{D}}$ : the charging locations are determined. Popular points, where many travels begin or end, should be assessed as potential charging points to decrease empty runs. The automated charging technologies should be installed to replace personnel.

$\mathrm{P}_{\mathrm{E}}$ : on one hand, the tariff structure and payment method are determined; on the other hand, the rate calculation method and the current values of variables used in the calculations are determined. Dynamic rates should be introduced to influence demands. The following relevant aspects are to be considered: current demands and capacities, sharing, ordering in advance.

$\mathrm{P}_{\mathrm{F}}$ : mobile application services are determined and specified. Mobil application planning is especially important for STA as most of the passenger handling functions are aided by mobile applications (e.g. ordering). The real-time and personalized information should be provided automatically.

$\mathrm{P}_{\mathrm{G}}$ : on-board services, especially infotainment services, are specified. Personalized, location-based information and entertainment should be provided.

$\mathrm{P}_{\mathrm{H}}$ : the functions regarding the use of services during travel and their operational logic are planned. Automated functions should be installed in order to replace personnel attendance (e.g. ticketing, entitlement checking, registration of boarding).

$\mathrm{P}_{\mathrm{I}}$ : on one hand, runs with and without passengers (runs to charging, parking, reallocation) are planned; on the other hand, the operative timetable is planned if the planned capacity cannot meet the current demands or the interchanges should be guaranteed. The real-time demand-capacity coordination and planning of shared runs are to be introduced.

$\mathrm{P}_{\mathrm{J}}$ : maintenance plans of AVs are determined. The input data, such as technical requirements or run mileage of $A V s$ are based on assumptions and forecasted data in the early phase. After the introduction the service, real-time diagnostic data are considered.

STA is planned either by operator or transport management center but close cooperation between participants is necessary (e.g. in order to provide a seamless mobility service). The local municipalities and infrastructure operators should be also involved in the planning process. 


\section{The information system of planning}

The required data groups for planning have been identified and summarized in Table II. Fig. 3. shows the model for the information system of planning.

TABLE II

DATA GROUPS

\begin{tabular}{|c|c|c|}
\hline Sign & Name & $\begin{array}{l}\text { Description } \\
\end{array}$ \\
\hline$\overline{\mathrm{D}_{U}}$ & user & $\begin{array}{l}\text { basic data of potential users } \text { (socio- } \\
\text { demographic characteristics } \\
\text { habits) in a given territory }\end{array}$ \\
\hline $\mathrm{D}_{\mathrm{T}}$ & territory & $\begin{array}{l}\text { territory attributes (e.g. road network, fix } \\
\text { stops), }\end{array}$ \\
\hline$D_{V}$ & technical & $\begin{array}{l}\text { technical data about vehicles, charging } \\
\text { facilities }\end{array}$ \\
\hline $\mathrm{D}_{\mathrm{S}}$ & survey & $\begin{array}{l}\text { raw, unprocessed data from the survey about } \\
\text { user expectations }\end{array}$ \\
\hline $\mathrm{D}_{\mathrm{P}}$ & $\begin{array}{l}\text { proce } \\
\text { surve }\end{array}$ & processed data of the survey \\
\hline$D_{0}$ & operation & $\begin{array}{l}\text { gerational data (e.g. current vehicle location, } \\
\text { ata about orders) }\end{array}$ \\
\hline $\begin{array}{l}D_{A^{-}} \\
D_{J}\end{array}$ & $\begin{array}{l}\text { planned } \\
\text { mobility service }\end{array}$ & $\begin{array}{l}\text { output of planning functions, index refers to } \\
\text { planning function (e.g. output of } \mathrm{P}_{\mathrm{A}} \text { is } \mathrm{D}_{\mathrm{A}} \text { ) }\end{array}$ \\
\hline
\end{tabular}

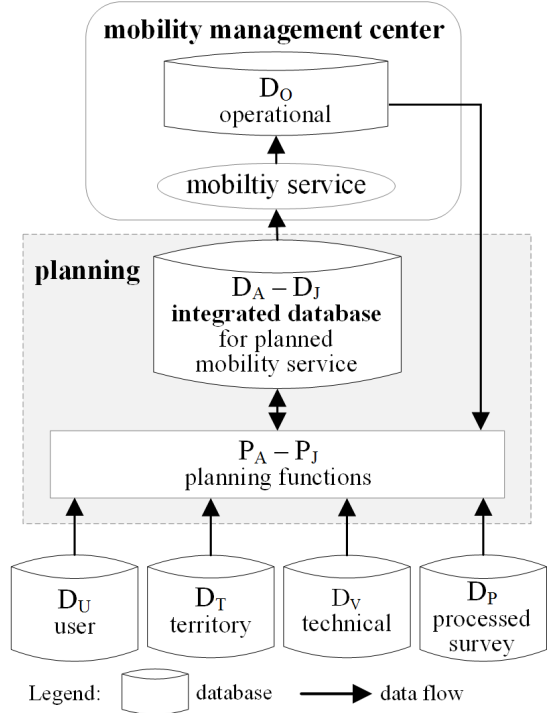

Fig. 3. Model for the information system of planning

The input data of the planning functions are $\mathrm{D}_{\mathrm{U}}, \mathrm{D}_{\mathrm{T}}, \mathrm{D}_{\mathrm{V}}, \mathrm{D}_{\mathrm{Q}}$ and $\mathrm{D}_{\mathrm{R}} . \mathrm{D}_{\mathrm{U}}, \mathrm{D}_{\mathrm{T}}$ and $\mathrm{D}_{\mathrm{V}}$ are provided by any third party (e.g. statistical office, municipality, manufacture). The source of $D_{S}$ is the questionnaire responses. Processed survey data $\left(D_{P}\right)$ are produced from raw survey data $\left(D_{S}\right)$; which are the key elements for user-centric, personalized service planning. The mobility service is accomplished according to data of planned mobility service $\left(\mathrm{D}_{\mathrm{A}}-\mathrm{D}_{\mathrm{J}}\right)$. These data are stored in an integrated database where all functions provide output data to. The mobility service is managed and supervised by a mobility management center which collects the data about the operation $\left(D_{0}\right)$, too. $D_{0}$ are used as an input for the operative planning functions $\left(\mathrm{P}_{\mathrm{I}}, \mathrm{P}_{\mathrm{J}}\right)$. The input and output data of the functions have been identified in detail (Table III).

Fig. 4. presents the input data of the functions. Output data of a function are used as input data for another function. Accordingly, the connections between functions are realized through the integrated database.
TABLE III

INPUT - OUTPUT DATA OF PLANNING FUNCTIONS

\begin{tabular}{|c|c|c|}
\hline Func. & Input & Output \\
\hline $\mathrm{P}_{\mathrm{A}}$ & $\begin{array}{l}\mathrm{D}_{\mathrm{U}} \text { : e.g. O-D matrix (frequency, } \\
\text { origins, destinations of trips), } \\
\mathrm{D}_{\mathrm{T}} \text { : e.g. density of population, distance } \\
\text { of public transportation stop }\end{array}$ & $\begin{array}{l}\mathrm{D}_{\mathrm{A}}: \text { travel demand, } \\
\text { estimated number of } \\
\text { passengers, rate of STA } \\
\text { types, modal-share }\end{array}$ \\
\hline $\mathrm{P}_{\mathrm{B}}$ & $\begin{array}{l}\mathrm{D}_{\mathrm{T}} \text { : e.g. location of service points; } \\
\mathrm{D}_{\mathrm{A}} \text { : travel demand, rate of STA types }\end{array}$ & $\begin{array}{l}D_{B} \text { : location of fix stop, } \\
\text { route, area }\end{array}$ \\
\hline $\mathrm{P}_{\mathrm{C}}$ & $\begin{array}{l}D_{\mathrm{T}} \text { : e.g. road network; } \\
D_{\mathrm{V}} \text { : general features of vehicles - } \\
\text { e.g. battery capacity; } \\
D_{\mathrm{A}} \text { : travel demands, estimated number } \\
\text { of passengers, rate of STA types; } \\
\mathrm{D}_{\mathrm{B}} \text { : location of fix stops, routes, areas }\end{array}$ & $\begin{array}{l}\mathrm{D}_{C}: \text { timetable (type } \mathrm{S}_{3}, \\
\mathrm{~S}_{4} \text { ), aggregated } \\
\text { mileage, number of } \\
\text { vehicles }\end{array}$ \\
\hline $\mathrm{P}_{\mathrm{D}}$ & $\begin{array}{l}D_{\mathrm{T}} \text { : e.g. road network; } \\
\mathrm{D}_{\mathrm{V}} \text { : general features of vehicles } \\
\text { (e.g. battery consumption rate), } \\
\text { general features of chargers (e.g. maxi- } \\
\text { mum energy per charge, charging time); } \\
\mathrm{D}_{\mathrm{B}} \text { : location of fix stops, routes, areas; } \\
\mathrm{D}_{\mathrm{C}} \text { : timetable, aggregated mileage }\end{array}$ & $\begin{array}{l}D_{\mathrm{D}} \text { : location of } \\
\text { charging stations, type } \\
\text { of chargers }\end{array}$ \\
\hline $\mathrm{P}_{\mathrm{E}}$ & $\begin{array}{l}\text { operational expectation - e.g. economic } \\
\text { indicator; } D_{\mathrm{A}} \text { : rate of STA types }\end{array}$ & $\mathrm{D}_{\mathrm{E}}$ : tariff system \\
\hline $\mathrm{P}_{\mathrm{F}}$ & $\begin{array}{l}\mathrm{D}_{\mathrm{G}} \text { : on-board services; } \\
\mathrm{D}_{\mathrm{H}} \text { : passenger handling functions }\end{array}$ & $\begin{array}{l}D_{F} \text { : specification of } \\
\text { application functions }\end{array}$ \\
\hline $\mathrm{P}_{\mathrm{G}}$ & $\begin{array}{l}\mathrm{D}_{\mathrm{F}} \text { : mobile application functions; } \\
\mathrm{D}_{\mathrm{H}} \text { : passenger handling functions }\end{array}$ & $\begin{array}{l}D_{G}: \text { specification of on- } \\
\text { board services }\end{array}$ \\
\hline $\mathrm{P}_{\mathrm{H}}$ & $\begin{array}{l}D_{\mathrm{F}}: \text { mobile application functions; } \\
\mathrm{D}_{\mathrm{G}} \text { : on-board services }\end{array}$ & $\begin{array}{l}\mathrm{D}_{\mathrm{H}} \text { : passenger handling } \\
\text { plans (boarding, security, } \\
\text { payment, checking) }\end{array}$ \\
\hline $\mathrm{P}_{\mathrm{I}}$ & $\begin{array}{l}D_{\mathrm{T}} \text { : e.g. road network; } \\
\mathrm{D}_{\mathrm{B}} \text { : location of fix stops, routes, areas; } \\
D_{\mathrm{C}} \text { : number of vehicle, timetable; } \\
D_{\mathrm{D}} \text { : location of charging stations; } \\
\mathrm{D}_{\mathrm{O}} \text { : ordering, status of vehicles }\end{array}$ & $\begin{array}{l}\mathrm{D}_{\mathrm{I}} \text { : operative } \\
\text { timetables, runs }\end{array}$ \\
\hline $\mathrm{P}_{\mathrm{J}}$ & $\begin{array}{l}\mathrm{D}_{\mathrm{C}} \text { : aggregated mileage, number of } \\
\text { vehicles, timetable; } \\
\mathrm{D}_{\mathrm{O}} \text { : diagnostic data; } \\
\mathrm{D}_{\mathrm{V}} \text { : general features of vehicles } \\
\end{array}$ & $\mathrm{D}_{\mathrm{J}}$ : maintenance plans \\
\hline
\end{tabular}

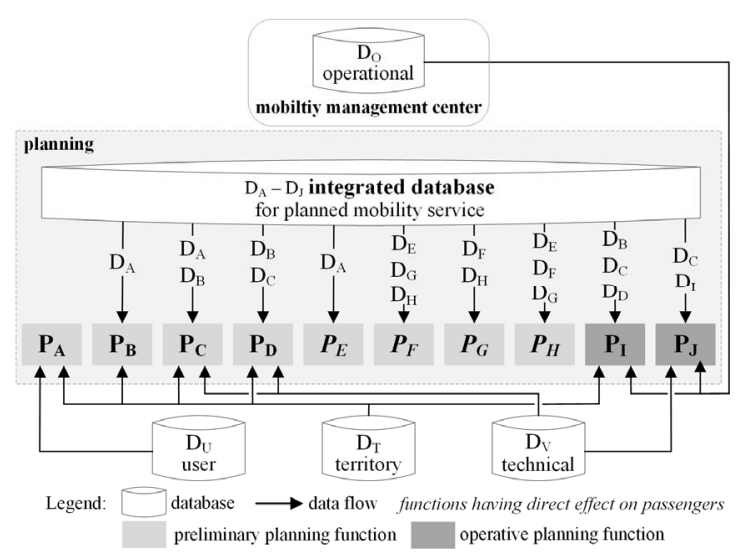

Fig. 4. Input data of functions

The functions having a direct effect on passengers (fee collection, information service planning functions) depend on the basic service. Accordingly, planning of these services $\left(\mathrm{P}_{\mathrm{E}}-\right.$ $\mathrm{P}_{\mathrm{H}}$ ) requires input data only from these functions. Operative planning is a persistent process. As more-and-more operational data are available the exactness of planning functions can be improved.

\section{Data collection and process method}

The following question groups have been incorporated in our questionnaire: 
I. socio-demographic characteristics,

II. current mobility habits,

III. altering mobility services.

As socio-demographic characteristics and current mobility habits influence strongly the use of STA types and expectations towards service, the mobility habits according to different motivations are revealed in question group I and II. Questions in group III are pertaining to expected service attributes of STA. The revealed expectations are used as input data to the planning functions.

Structure of the questionnaire is presented on Fig. 5. The questions are indicated by boxes. The type of questions is represented by colours. The first index cites the number of a question group. One question refers to a characteristics or a mobility habit. User-related questions are classified according to socio-demographic characteristics, current mobility habits or willingness to use any STA type. STA service-related questions are classified whether it refers to a basic service (movements or fee collection) or an information service. One attribute as a variable may take several values; the values are represented by options. In some cases, sub-questions extend the question to reveal additional attributes. Multiple choice [25] and rating question types have been introduced. In the case of rating questions, a so-called Likert-scale [26] is used where the set of values is 1-3. In the case of sub-questions, the structure of the questions is indicated by a matrix.

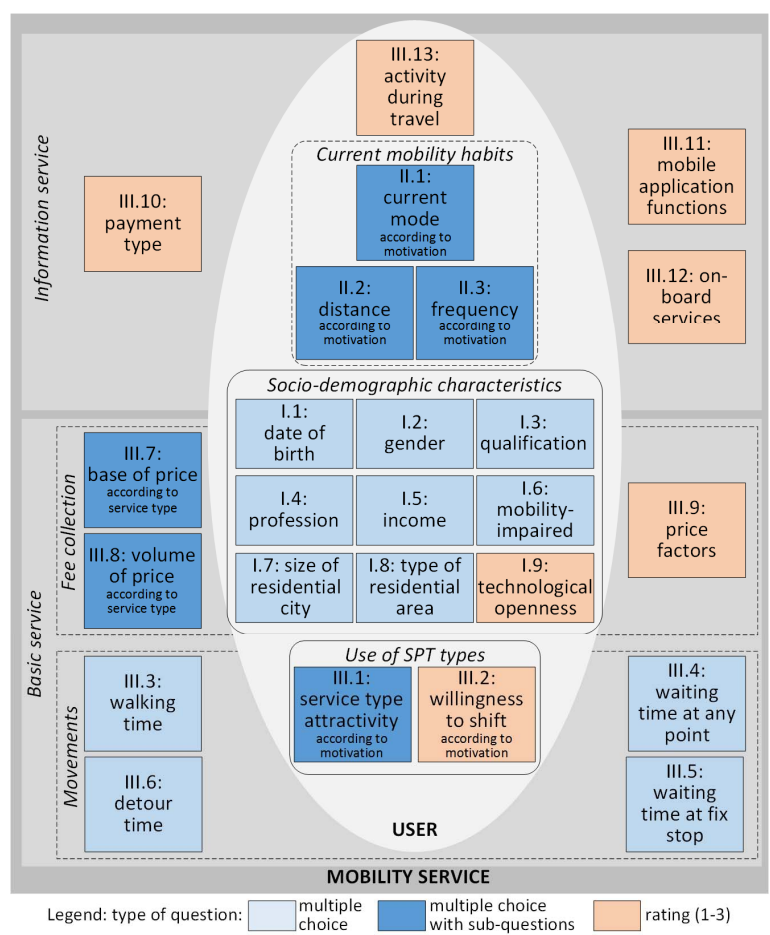

Fig. 5. Structure of questionnaire

The $\mathrm{D}_{\mathrm{P}, \mathrm{m}}$ as input data have been assigned to the planning functions on Fig. 6. Input data from the processed survey are not needed for planning functions $P_{D}, P_{J}$ as supplementary operational activities are planned in these cases.

The raw data collected by the survey $\left(D_{\mathrm{S}}\right)$ are processed by queries. The processed survey data $\left(D_{P}\right)$, which are used as an input data for mobility service planning, are resulted by the queries. The responses to questions in group III are used in the queries $\left(\mathrm{Q}_{\mathrm{m}, \mathrm{n}}\right)$ as input data. The first index $(m)$ refers to the number of question in group III (see Fig. 5.). For instance, the following query can be formulated: $\mathrm{Q}_{13,1}$ : how important is the WiFi for the respondents as an on-board service?

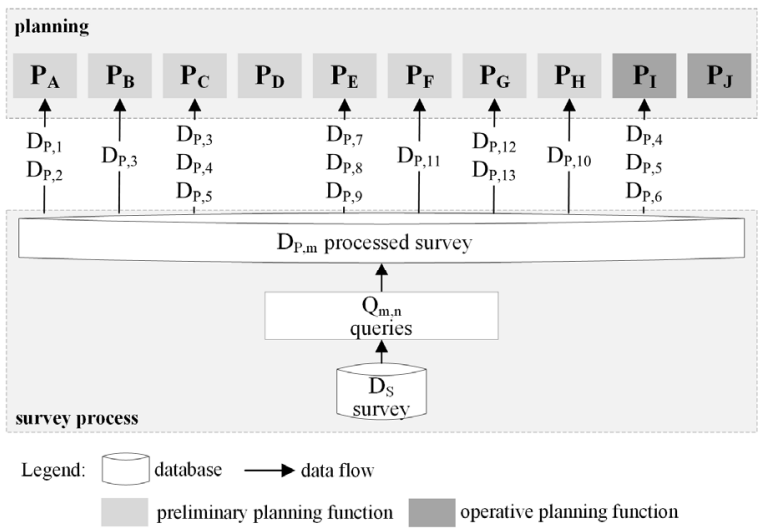

Fig. 6. Processed survey data as input to planning functions

Values derived from responses in question group I or II are used in the query conditions. For instance, the $\mathrm{Q}_{13,2}$ query is prepared from the $\mathrm{Q}_{13,1}$ query by adding the following condition: only the respondents born between 1990 and 2000 are considered. The values of the date of birth are sourced from I.1. question.

The sub-groups of processed survey data $\left(\mathrm{D}_{\mathrm{P}, \mathrm{m}}\right)$ have been introduced as output data of a certain query (in Table IV.)

TABLE IV

SUb-GRoups OF SURVEY PRocessed DATA ( $\mathrm{D}_{\mathrm{P}, \mathrm{m}}$ )

\begin{tabular}{llll}
\hline \hline $\mathrm{m}$ & \multicolumn{1}{c}{ Description } & $\mathrm{m}$ & \multicolumn{1}{c}{ Description } \\
\hline 1 & estimation of STA type & 7 & expected base of fee \\
2 & willingness to shift & 8 & expected volume of fee \\
3 & tolerated walking time & 9 & volume of tolerated fee factors \\
4 & tolerated waiting time & 10 & expected payment methods \\
& at any point & 11 & expected mobile application \\
5 & tolerated waiting time & & services \\
& at fix stop & 12 & expected on-board services \\
6 & tolerated detour time & 13 & estimation of activity types \\
\hline \hline
\end{tabular}

In certain cases, the expectations towards mobility service cannot be surveyed satisfactorily (e.g. imperfect data), or only some data about socio-demographic characteristics or mobility habits are available. To handle these cases correlations between socio-demographic characteristics or mobility habits and service attributes should be revealed. The processed survey data can be determined by the application of correlations if the independent variables, namely, the responses about socio-demographic characteristics or mobility habits are available.

A pilot survey has been executed in order to check the feasibility and clarity of the questionnaire. 25 respondents (students and experienced colleagues) were selected mostly from our university. Considering their comments, the questionnaire was modified. Although it was a test sample, relevant consequences could be already drawn. For instance, the technologically opened respondents accept AVs more, the 
individual car users prefer flexible STA types, the rather fix SPT types are preferred for less flexible travel motivations (e.g. working). The correlations can be verified, and further ones can be revealed after the accomplishment of the survey.

\section{CONCLUSION}

Our study provides planning principles for mobility services based on AVs. Since these solutions are still in very early development phase the results have high relevance for innovation purposes. The main contributions are the model of the information system for planning functions and the data collection method. A significant part of the inputs to the planning functions is sourced by the questionnaire. The structure of the survey is formed according to the input requirements of planning functions.

During the modelling of the information system for planning the following key findings were identified:

- the planning of functions having a direct effect on passengers requires input data only from these functions,

- the planning of supplementary operational activities does not require input data from the processed survey,

- correlations between questions can be used to provide input data for a planning function if the expectations towards a mobility service (question group III.) cannot be surveyed adequately.

We faced, as a lesson learnt, that user expectations can be measured by stated preferences as the mobility services based on AVs are still barely available.

During the survey, we are going to ask at least 500 potential users via internet. The sample contains persons, who have experience with AVs and persons, who do not. In this way, the results can be compared. In addition, our further research focuses on the elaboration of the planning functions. The details of the transformation of input data to output data will be revealed with consideration of the identified novelties.

\section{REFERENCES}

[1] J-F. Cordeau, G. Laporte, J-Y. Potvin, M.W.P. Savelsbergh. "Transportation on Demand," in Handbooks in Operations Research and Management Science: Transportation. Vol 14, North Holland, 2007, pp. 429-466. DOI: 10.1016/S0927-0507(06)14007-4

[2] L. Davison, M. Enoch, T. Ryley, M.Quddus, C.Wang. (2013). A survey of Demand Responsive Transport in Great Britain. Transport Policy 31, pp. 47-57. DOI: $10.1016 /$ j.tranpol.2013.11.004

[3] D.J. Fagnant and K.M. Kockelman. (2014). The travel and environmental implications of shared autonomous vehicles, using agentbased model scenarios. Transportation Research Part C: Emerging Technologies. 40, pp. 1-13. DOI: 10.1016/j.trc.2013.12.001

[4] W. Gruel, J.M. Stanford. (2016) Assessing the long-term effects of autonomous vehicles: a speculative approach. Transportation Research Procedia 13, pp. 18-29. DOI: 10.1016/j.trpro.2016.05.003

[5] S. Szigeti, C. Csiszár, and D. Földes. (2017). Information Management of Demand-Responsive Mobility Service Based on Autonomous Vehicles. Procedia Engineering. 187, pp. 483-491. DOI: 10.1016/j.proeng.2017.04.404

[6] T. Tettamanti, I. Varga, and Z. Szalay. (2016). Impacts of Autonomous Cars from a Traffic Engineering Perspective. Periodica Polytechnica Transportation Engineering. 44(4), pp. 244-250. DOI: 10.3311/PPtr.9464
[7] A.M. Pereira, H. Anany, O. Pribyl, and J. Prikryl, "Automated Vehicles in Smart Urban Environment: A Review," in Smart City Symposium 2017 (SCSP2017), Prague, 2017. DOI: 10.1109/SCSP.2017.7973864

[8] E. Adell, A. Várhelyi, and L. Nilsson, "The Definition of Acceptance and Acceptability," in Driver Acceptance of New Technology: Theory, Measurement and Optimization, CRC Press, 2014, pp. 11-21.

[9] N. Merat, R. Madigan, and S. Nordhoff, "Human Factors, User Requirements, and User Acceptance of Ride-Sharing in Automated Vehicles," International Transport Forum, Paris, Discussion Paper, 2017.

[10] R. Madigan, T. Louw, M. Dziennus, T. Graindorge, E. Ortega, M. Graindorge, and N. Merata. (2016). Acceptance of Automated Road Transport Systems (ARTS): An Adaptation of the UTAUT Model. Transportation Research Procedia. 14, pp. 2217-2226. DOI: 10.1016/j.trpro.2016.05.237

[11] R. Krueger, T.H. Rashidi, and J.M. Rose. (2016). Preferences for shared autonomous vehicles. Transportation Research Part C: Emerging Technologies. 69, pp. 343-355. DOI: 10.1016/j.trc.2016.06.015

[12] A. Alessandrini, R. Alfonsi, P.D Site, and D. Stam. (2014). Users' preferences towards automated road public transport: results from European surveys. Transportation Research Procedia. 3, pp. 139-144. DOI: 10.1016/j.trpro.2014.10.099

[13] J. Piao, M. McDonald, N. Hounsell, M. Graindorge, T. Graindorge, and N. Malhene. (2016). Public Views towards Implementation of Automated Vehicles in Urban Areas. Transportation Research Procedia. 14, pp. 2168-2177. DOI: 10.1016/j.trpro.2016.05.232

[14] D. Christie, A. Koymans, T. Chanard, J.M. Lasgouttes, and V. Kaufmann. (2016). Pioneering driverless electric vehicles in Europe: the City Automated Transport System (CATS). Transportation Research Procedia. 13, pp. 30-39. DOI: 10.1016/j.trpro.2016.05.004

[15] S. Nordhoff, J. de Winter, R. Madiga, N. Merat, B. van Arem, and R Happee, "User acceptance of automated shuttles in Berlin-Schöneberg: A questionnaire study," working document, 2017.

[16] INRIX, "Identifies Top U.S. Cities for Shared Highly Autonomous Vehicle Deployment," US, 2017. http://inrix.com/

[17] L. Owczarzak and J. Zak. (2015). Design of passenger public transportation solutions based on autonomous vehicles and their multiple criteria comparison with traditional forms of passenger transportation. Transportation Research Proedica. 10, pp. 472-482. DOI: 10.1016/j.trpro.2015.09.001

[18] D. Nicolaides, D. Cebon, and J. Mile, "An autonomous taxi service for sustainable urban transportation," in Proceeding of 2017 Smart City Symposium Prague (SCSP2017), Prague, 2017. DOI: 10.1109/SCSP.2017.7973353

[19] ITF, "Shared Mobility Simulations for Helsinki," International Transport Forum, Paris, France, Report, 2017

[20] O.J. Ibarra-Rojas, F. Delgado, R. Giesen, J.C. Muñoz. (2015). Planning, operation, and control of bus transport systems: A literature review, Transportation Research Part B: Methodological. 77, pp. 38-75. DOI: 10.1016/j.trb.2015.03.002

[21] C. Csiszár, D. Földes. (2018). System Model for Autonomous Road Freight Transportation Promet-Traffic \& Transportation. 30(1), pp. 93103. DOI: $10.7307 /$ ptt.v30i1.2566

[22] Y. Shiftan, S. Kaplan, S. Hakkert. (2003). Scenario building as a tool for planning a sustainable transportation system. Transportation Research Part D: Transport and Environment. 8, pp. 323-342. DOI: 10.1016/S1361-9209(03)00020-8

[23] S. Guo, Y. Liu, K. Xu., D.M. Chiu, "Understanding Passenger Reaction to Dynamic Prices in Ride-on-demand Service," in Proceeding of Pervasive Computing and Communications Workshops, Kona, USA, 2017. DOI: 10.1109/PERCOMW.2017.7917517

[24] M. Stiglic, N. Agatz, M. Savelsbergh, M. Gradisar. (2017). The benefits of meeting points in ride-sharing systems. Transportation Research Part B: Methodological. 82, pp. 36-53. DOI: 10.1016/j.trb.2015.07.025

[25] T.M. Haladyna, "Guidelines for Developing MC Items," in Developing and Validating Multiple-Choice Test Items. Routledge Taylor \& Francis Group, 2011, pp. 97-127.

[26] T. Nemoto, D. Beglar, "Developing Likert-Scale Questionnaires," in Proceeding of JALT2013, Tokyo, 2014. 